\title{
Speech Act Theory and Its Implications to English Teachers
}

\author{
Chen Lei, Zhu Qinghui, Lei Zheqing \\ Department of Foreign Language, Sanya Aviation \& Tourism College, Hainan Province, China \\ 149454972@qq.com
}

\begin{abstract}
Briefly describe the Speech Act Theory and explain how language teachers benefit from the insights it provides into language use. Discuss whether and how these insights might be realized in teaching materials/strategies. It attempts to examine how the knowledge of SAT helps teachers understand what learners need to know to achieve communicative competence and how it can be realized in classes. Sociolinguistic competence is an important element of communicative competence and by raising learners' awareness of using appropriate SAS with more communicative approaches. Finally it posits that reading competence should be included in communicative competence and through SA training, advanced students will learn to grasp an accurate indication of the author's intention, which facilitates the overall communicative confidence of learners.

Index Terms - Speech Act Theory, Sociolinguistic competence, teaching approaches, Reading competence

\section{Introduction}

This essay will look at speech act theory (SAT) first from a historical account of how it developed. Then, it will give some description of SAT and look at some criticisms. I will next investigate how an understanding of SAT can develop communicative competence including sociocultural competence and reading competence in the CLT classroom, with illustrations from my own experiences.
\end{abstract}

\section{What is Speech Act Theory}

Although Speech Act Theory (SAT) and its implications for English Language Teaching (ELT) are currently mostly found in pragmatics and sociolinguistic literature, SAT was originally brought up as a concept in philosophy of language by Austin in the 1960s. According to Thomas (1995), Austin and his research group point out that studies should be shifted from the effort of refining everyday language to observe and find out how ordinary people communicate effectively with the everyday language as it is. Austin, then, as one of the 'ordinary language philosophers' (ibid: 29) and 'father of pragmatics', (ibid: 28) shed light on a linguistic frustration which was known as limitations of truth conditional semantics. In his book How to do things with words, he shifts his focus to differentiate 'the truth-conditional aspect of what a statement is' from 'the action it performs' (ibid: 49)[1]. In short, it is what speakers mean and what listeners actually grasp from conversations that should be studied. This was where utterances began to be seen as actions from the perspective of functions.
Recent researchers refer to SA as a 'function unit' (Cohen 1996: 384; Baleghizadeh 2007:146) during communication or simply an action performed through utterances (Yule 1996: 47) [2]. However, the term SA was originally used by Austin (1960: 52) to refer to an utterance and the 'total situation in which the utterance is issued'. In the summary of Austin's (1962) SAT, Cohen (1996), Thomas (1995) and Yule (1996) write about three types of meaning in utterances: locutionary meaning/force, illocutionary meaning/force and perlocutionary meaning/force. The first represents the literal meaning, the second stands for the social function and the third is the meaning inferred in a certain given context. Giving an example, in the utterance of 'it is cold in this room', the locutionary meaning would be that the speaker is stating a fact that regarding the temperature in the room. Its illocutionary meaning is that the speaker is trying to make a request to switch on the heater or simply complaining. The actual outcome that occurs as a result of the utterance in a particular context regardless of what is said or meant is referred to as perlocutionary.

Alston (1991) and Cohen (1996) point out that another scholar, Searle, makes a great contribution to the philosophy of language in terms of his developing a theory of illocutionary acts from his tutor in Oxford, Austin[3]. Searle (1991) refers to SA specifically as illocutionary acts, which he also classifies as 'language acts' or 'linguistic acts' (ibid: 254). Searle (ibid) argues linguistic communication fundamentally involves acts and the smallest unit of language communication is not a word or a sentence, but the SA that has been completed. To summarize, Searle (ibid: 255) argues that, if we hear an utterance, it is logical to assume that the person making it intends to communicate meaning of some kind, therefore the making of the utterance is what he means by SA. He (ibid) also uses promising as an example of an illocutionary act to analyze SA.

Based originally on Austin's (1962) felicity conditions, in order to successfully perform a SA and let them be recognized by hearers, Searle (1991: $81 ; 1996: 50)$ argues there are five conditions that need to be distinguished: input-output / general conditions, preparatory conditions, content conditions, sincerity conditions and essential conditions. These conditions provide the basis for different classifications of SA.

Grewendorf and Meggle (2002: preface) summarize that Searle presents a taxonomy of SA against Wittgenstain's argument that language has an endless variety. Searle claims that there are only five basic sorts of things we can do with 
language. Searle (2002: 5) suggests that the five essential types of SA are the assertive, directives, commissives, expressives and declarations. Cohen (1996: 384) elaborates the first one as 'representatives' which includes assertions, claims and reports. Searle (1991:81) justifies his classification firstly by the fact that it is rooted in 'illocutionary point/purpose' (ibid), which is the crucial condition of SA, then by an analysis of meaning (Searle: 2002: 6), which is fully explained in another book called Intentionality published in 1983.

Nevertheless, it remains controversial what the best way to classify SA is. Not every researcher agrees with Searle's classification. Ballmer and Brennenstuhl (1981: 55-61) criticize Searle's classification as having seven defects, including insufficient examples, circular definitions and not giving a consistent principle of classification. As an alternative, they (ibid: 58-59) provide a list containing eleven properties that they believe a classification of SA should possess[4].

There is another approach based on the structure of utterances to make a distinction among types of SA, which are known as direct and indirect speech acts (Searle: 1991; Yule 1996: 54). A direct SA is when the relationship between a structure and function is direct, whereas an indirect speech is, on the contrary, when the relationship of the two is indirect (Yule 1996: 54-55). For example, if I change the statement 'I can't hear you.' into 'I order you to speak louder.', the latter will be functioning as a direct speech act. If I change the statement to 'Would you please speaker louder?', it is then used as a request and functions as an indirect SA. Most of the imperatives are rarely used to issue requests and alternatively, indirectly requesting is normally used (Cohen 1996: 384).

What we have discussed about SAT so far mainly falls into the category of standard theories. They focus on speakers' intention and hearers' recognition (Clark and Carlson: 1991). Clark and Carlson (ibid) take issue with what the standard theories that originated from Austin lack. They (ibid) argue that the standard theories about SA neglect the fact that there might be more than one hearer in communication, thereby the intentions of the speakers to different hearers vary and the roles of the hearers are different as well. They (ibid: 196) suggest adding a new layer of illocutionary act called informatives, with the purpose of completing SAT in terms of making it possible to justify what speakers do with the words when more than one participant/hearer comes up[5].

\section{How Does SAT Benefit Language Teachers and How Can It be Realized Through Strategies and Teaching Materials}

In my teaching context in a college in China, most of my colleagues teach pragmatics on an ad hoc basis, including teaching SA, if any. The textbook we use is called 21st Century Practical English, published by Fudan University, which does not have systematic SA sessions that teachers can follow. The textbook includes some sporadic mentions about how to request and apologize, but they are not wellcontextualized. For most of my colleagues, it seems that SA is not teachable and can only be picked up on an ad hoc basis, as a result, they are unwilling to teach them in class. At best, they will simply follow the textbook. This teacher belief results in communicative failures for L2 learners when communicating with L1 speakers in the real world. The teaching of SA, in my opinion, indeed plays an important role in developing learners' 'communicative competence' (Hymes 1972) [6], which is one of the main goals of modern language education for a wide range of English teachers (Hedge 2000: 44). This paper will support this argument from the following aspects.

\subsection{The significance of speech act set}

Many types of speech act set (SAS) can be seen in real life such as: apologize, request, promise, complain and compliment. Because we come across them so often in reality, learners would like to, and should get, a basic understanding of how these SA can be realized in utterances. The set of realization patterns and strategies in utterances used by L1 English speakers is referred to as the speech act set by Olshtain \& Cohen (1983) and Cohen (1996: 385). Cohen (ibid: 386) argues that the incorrect use of SA may impede effective communications to different degrees. Giving an example of how L1 speakers usually make an apology according to Cohen's (ibid) SAS is:

1. Direct apologetic utterance including performative verbs. Eg. I'm sorry I'm late.

2. Explaining the reason for transgression. Eg. I missed my bus.

3. Admitting responsibility for transgression. Eg. I should've left earlier.

4. Making amends.

Eg. How about I buy you lunch?

5. Saying the transgression will not recur.

Eg. I promise it won't happen again.

In reality, people apologize in different ways based on their relationships to the hearers. Most people make apologies by selecting the patterns according to specific contexts and personal preferences. As a teacher, it is tempting to be guided only by what is said in textbooks, whereas teachers with a broader knowledge of SAS are in a better position to broaden the scope of learners' communicative competence. This is because learners will have a richer selection to choose from to apologize they way they need to in real life situations. In other words, teachers who are more informed about SAS are better prepared to furnish the learners with a rich range to realize a greater communicative competence.

SAS can be introduced through teaching materials such as textbooks. Unfortunately, nothing related to this can be found in the textbook used in the college where I teach. Baleghizadeh (2007: 149) points out that the strategic-based use of SA is still insufficiently covered in English language teaching textbooks and those that contain SA teaching present teachers at best with sample dialogues and role plays. According to Baleghizadeh's (ibid) research, there are, however, still a handful of textbooks that apply SAS very well, such as New Interchange by Richarch et al (ibid). Baleghizadeh (ibid) 
provides an extract from this textbook (see appendix 1) to illustrate how the concept of SAS along with the example of making an apology gets to be realized in teaching materials.

From this activity, we can roughly see that the rationale behind it is to guide learners to understand different strategies of making apologies and to compare the different SAS strategies from the cross-cultural perspective. Baleghizadeh (ibid) considers this activity an effective one because it gives students an opportunity to raise their awareness of the language. Nevertheless, from the point of view of teaching methods, I will argue a bit later in 2.3 , this activity can be modified to concur more with communicative language teaching for helping students achieve an enhancement of communicative competence.

\subsection{Sociolinguistic competence and SA}

For most experienced teachers, it is not difficult to notice that there is a difference between the students' grammatical competence and their communicative competence (Baleghizadeh 2007; Zhao and Throssell 2011). This phenomenon in China is displayed through the gap between the high examination scores in class and poor communicative performance with L1 English speakers in reality. With an increasing need to communicate with people from all over the world, high scores in examinations alone can no longer satisfy Chinese English learners. Apart from good academic performance in school, most of my students aim at effectively communicating with L1 English speakers in real life. How to improve their communicative competence, hence, has become one of the major questions that teachers endeavour to answer. According to Canale (1983), one of the five major elements of communicative competence is sociolinguistic competence, which includes social, pragmatics and cultural aspects[7]. SA realization plays a very important role in developing students' sociolinguistic competence. Raising awareness of selecting the most appropriate SAS and strategies will provide students with a better cross-cultural communication experience. At the same time, from a large scale empirical study known as CrossCultural Speech Act Research Project (CCSARP), Cohen (1996: 388) argues that sociocultural and sociolinguistic abilities are crucial in successfully producing SA utterances. Cohen (ibid) refers to sociolinguistic ability as the 'skill of respondents at selecting appropriate linguistic forms in order to express the particular strategy used to realize the SA such as expressing regret in an apology...'. To what extent learners can manage actual linguistic forms to realize SA is shown through sociolinguistic competence (ibid). Differences between linguistic forms in different contexts can be subtle and remain unnoticed by L2 speakers. For example, Cohen (ibid) mentions the differences between 'very sorry' and 'really sorry' are not as obvious to L2 speakers as they are to L1 speakers. L2 speakers often do not realize that in terms of sincerity, 'really sorry' sounds more sincere and has an indication of deeper regret. Through giving learners training on raising their awareness of different degrees of regret between 'really sorry' and 'very sorry', students will be more likely to apologize exactly the way they intend to. Although not much literature regarding clear and direct teaching of speech acts can be found, Cohen (1996) presents a study carried out by Olshtain and Cohen in 1990 in Israel to illustrate that, even the most subtle differences between the 'realizations of SA strategies and consideration of situational features' (ibid: 410) is actually teachable in EFL classrooms.

Nevertheless, this does not suggest that simply laying out the possible alternatives of speech act patterns will be of great help to students (Cohen 1996; Zhao and Throssell 2011; Tatsuki and Houck 2010). Cohen (1996) emphasizes the importance of matching the specific situations as well as related social factors, with the 'most common realizations of the speech act' (ibid: 413). Cohen (ibid: 413-415) summarizes five steps: diagnostic assessment, sample dialogues, evaluation of situation, role-play activities and feedback and discussion. The rationale behind the five steps is that, as Cohen (ibid: 415) argues, learners should firstly have a rich exposure to the general realization of each pattern, then be guided to a better understanding of related factors including sociocultural factors, and lastly be given a chance to practice the SA patterns. However, I would argue that the five steps cannot help learners improve their communicative competence to its greatest extent, as explained in the following point.

\subsection{Teaching approaches and SA}

As we have discussed, teaching SA is meant to develop learners' communicative competence. Also, there is a strong sense that an understanding of SA for teachers should lead to a development of communicative competence in learners. Communicative language teaching (CLT) is now widely considered a robust approach for the development of communicative competence (Cohen 1996; Hedge 2000). However, in the same literature (Cohen 1996; Baleghizadeh 2007), the steps and activities presented to utilize SAT still follow a more traditional language teaching approach, such as presentation-practice-production (ppp) and an adjusted version of ppp (add pre-assessment before presentation and feedback after production), which at best is a very weak version of CLT. Taking Cohen's (1996: 413-415) five steps that we talked about above for example, the first step is to diagnostically assess students' existing awareness of SA in general. Teachers then present students with model dialogues, followed by the situational evaluation to practice learners' awareness of the factors involving selecting SAS. The fourth step is the roleplay activities for learners to produce the use of SA, and finally we have the feedback and discussion. The approach of the whole process is essentially ppp which I would argue, does not apply the principles of CLT strongly enough.

Now let us take a further look at the extracted apology class activity we talked about in 2.1 of this paper. It first presents four speech strategies of making an apology, then gives students some time to reflect on the ways to apologize in their own culture as well as in their personal preference, the next step is for students to practice the strategies through listening to conversations. Compared to the five steps Cohen (1996) suggests, this approach is better because, before practicing, it gives learners an opportunity to discuss the 
potential differences between making an apology in their own culture and in the target language culture. With that awareness in mind, the practice followed will be more effective.

However, both the approaches have a paucity of communicativeness. I would argue that one of the main realizations of CLT, task-based approach, can be implemented in SA lessons. For example, instead of presenting learners with the selection of speech strategies for making an apology in the first step, we could give learners a task that contains both appropriate and inappropriate ways to apologize in two different sociocultural contexts. Alternatively, learners can work on a task that is topic-centered (Tatsuki and Houck 2010) such as how to greet each other in English speaking cultures. This way, learners will have a chance to proactively notice the gap between suitable and unsuitable speech strategies in different sociocultural contexts. By completing tasks in groups guided by teachers, students will develop an awareness of using related SAS appropriately. Then through post-tasks, learners will have a chance to notice the gap again. Finally, this can be followed by a short summary and discussions, which will be of benefit for learners.

\subsection{Reading competence and $S A$}

When talking about communication, many people tend to refer to the interaction during it exclusively as spoken interaction. Hedge (2000: 188), on the other hand, points out that the term interactive also indicates the reading process including second language reading because 'it describes a dynamic relationship with a text as the reader struggles to make sense of it' [8]. In order to improve learners' communicative competence, reading ability should also be taken into consideration. For upper-intermediate and advanced learners, like some of the learners in my context, what is challenging when reading English articles especially authentic materials such as magazines and newspapers, is not the literal meaning of sentences but what the writers' intention behind the article is i.e. what the writers are really trying to express. It is frustrating to be unable to understand the author's true implication when you actually comprehend the meaning of every single word in the sentences. To better understand the author's implication and intention, SA needs to be introduced in reading classes and authentic teaching materials can be utilized. Cohen (1996: 384) argues that when teaching SA to L2 speakers we should focus on the 'explicit and literal significance' rather than on communicated intentions such as irony. However, from my own teaching experience, for upperintermediate and advanced learners, it is the failure to understand indirect SA such as sarcasm that leaves learners no choice but to remain at the intermediate plateau level. Advanced learners should be encouraged to read between the lines and for example understand what statement a writer was making when they wrote a satirical spoof of a story or article depicting caricatures of prominent personalities.

We will now look at an extract from an article called Save the City in The Economist. 'Attacks on bankers by protesters from Occupy Wall Street, Occupy London and Occupy any city where a financier might have the temerity to turn a quick buck have spiced up the dreary economic news of the past year.'

To understand the irony of this utterance, learners need to be prepared with the sociocultural background of what Occupy Wall Street refers to. Then they need to be guided to notice two particular expressions and think about why the author uses them: attack and turn a quick buck. Those are all radical expressions which could easily have been replaced with neutral words. For example, the author could have replaced 'attack' with 'criticism' and 'turn a quick buck' with 'make money'. From the above analysis, it is apparent that the author has a bias towards the financiers as expressed by his sarcastic depiction of the protesters. In this example, students can infer that when extreme words are used as SAS in place of neutral words, the utterance may be considered ironic or sarcastic, and can suggest a bias on the part of the author.

\section{Conclusion}

This paper starts with the introduction of SAT and gives a historical review of SAT, mainly based on the works of Austin and Searle. Then it gives more recent views including a few critics of Searle's SA taxonomy. In the second part, it attempts to examine how the knowledge of SAT helps teachers understand what learners need to know to achieve communicative competence and how it can be realized in classes. It argues that the SAS is essential for teaching SAT. Furthermore, sociolinguistic competence is an important element of communicative competence and by raising learners' awareness of using appropriate SAS with more communicative approaches such task-based teaching, learners will be more likely to achieve communicative competence. Finally it posits that reading competence should be included in communicative competence and through SA training, advanced students will learn to grasp an accurate indication of the author's intention, which facilitates the overall communicative confidence of learners. These points, however, need more future empirical studies to see how effective they are in actual classes.

\section{References}

[1] Austin, J. L. (1962). How to Do Things with Words. New York: Oxford University Press.

[2] Baleghizadeh, S. (2007). Speech acts in English language teaching, Iranian Journal of Language Studies Vol. 1/2: 143-154

[3] Alston, W.P. (1991). 'Searle on Illocutionary Acts' in Lepore, E. \& Van Gulick, R. (eds.) John Searle and His Critics. pp57-80

[4] Ballmer, Th. \& Brennenstuhl, W. (1981). Speech Act Classification. Bochum: Springer-Verlag Berlin Heidelberg

[5] Clark, H.H. \& Carlson, T.B. (1991). 'Speech Acts and Hearers' Beliefs' in Davis,S. (ed.) Pragmatics A Reader. New York: Oxford University Press. pp177-198

[6] Hymes, D.H. (1972). 'On communicative competence' in Pride, J.B. and Holmes, J. (eds.): Sociolinguistics. Harmondsworth: Penguin. pp. 26993

[7] Canale, M. (1983). 'From communicative competence to communicative language pedagogy' in Richards, J.C., and Schmidt, R. (eds.), Language and communication. Harlow: Longman.

[8] Hedge, T. (2000). Teaching and Learning in the Language Classroom. New York: Oxford University Press. 